\title{
Role of IL-10 in Resolution of Inflammation and Functional Recovery after Peripheral Nerve Injury
}

\author{
Bruno Siqueira Mietto, ${ }^{1,2}$ (D) Antje Kroner, ${ }^{1}$ Elizabeth I. Girolami, ${ }^{1}$ Eva Santos-Nogueira, ${ }^{1}$ Ji Zhang, ${ }^{3}$ \\ and Samuel David ${ }^{1}$ \\ ${ }^{1}$ Centre for Research in Neuroscience, The Research Institute of the McGill University Health Centre, Montreal, Quebec, Canada H3G 1A4, ${ }^{2}$ Institute of \\ Biomedical Sciences, Centre of Health Sciences, Federal University of Rio de Janeiro, Brazil 21941902, and ${ }^{3}$ Neurology and Neurosurgery, Alan Edwards \\ Centre for Research on Pain, and Faculty of Dentistry, McGill University, Montreal Quebec, Canada H3A 0G1
}

A rapid proinflammatory response after peripheral nerve injury is required for clearance of tissue debris (Wallerian degeneration) and effective regeneration. Unlike the CNS, this response is rapidly terminated in peripheral nerves starting between 2 and 3 weeks after crush injury. We examined the expression and role of the anti-inflammatory cytokine IL-10 in the resolution of inflammation and regeneration after sciatic nerve crush injury in mice. IL-10 mRNA increased over the first $7 \mathrm{~d}$ after injury, whereas at the protein level, immunofluorescence labeling showed IL- $10^{+}$cells increased almost 3 -fold in the first 3 weeks, with macrophages being the major cell type expressing IL-10. The role of IL-10 in nerve injury was assessed using IL-10-null mice. Increased numbers of macrophages were found in the distal segment of IL-10-null mice at early ( $3 \mathrm{~d}$ ) and late (14 and $21 \mathrm{~d}$ ) time points, suggesting that IL-10 may play a role in controlling the early influx and the later efflux of macrophages out of the nerve. A chemokine/cytokine PCR array of the nerve $24 \mathrm{~h}$ after crush showed a 2- to 4-fold increase in the expression of 10 proinflammatory mediators in $I L-10^{-1-}$ mice. In addition, myelin phagocytosis in vitro by LPS stimulated bone-marrow-derived macrophages from IL-10-null mice failed to downregulate expression of proinflammatory chemokines/cytokines, suggesting that IL-10 is required for the myelin-phagocytosis-induced shift of macrophages from proinflammatory to anti-inflammatory/pro-repair phenotype. The failure to switch off inflammation in IL-10-null mice was accompanied by impaired axon regeneration and poor recovery of motor and sensory function.

Key words: anti-inflammatory cytokine; IL-10; inflammation; macrophage; peripheral nerve; regeneration

Significance Statement

An appropriately regulated inflammatory response after peripheral nerve injury is essential for axon regeneration and recovery. The aim of this study was to investigate the expression and role of the anti-inflammatory cytokine IL-10 in terminating inflammation after sciatic nerve crush injury and promoting regeneration. IL-10 is rapidly expressed by macrophages after crush injury. Its role was assessed using IL-10-null mice, which showed that IL-10 plays a role in controlling the early influx and the later efflux of macrophages out of the injured nerve, reduces the expression of proinflammatory chemokines and cytokines, and is required for myelin-phagocytosis-induced shift of macrophages from proinflammatory to anti-inflammatory. Furthermore, lack of IL-10 leads to impaired axon regeneration and poor recovery of motor and sensory function.

\section{Introduction}

Peripheral nerve injury results in degeneration of damaged axons and their myelin sheaths distal to the site of the injury, a process

Received June 2, 2015; revised 0ct. 13, 2015; accepted Nov. 9, 2015.

Author contributions: B.S.M., A.K., E.I.G., J.Z., and S.D. designed research; B.S.M., A.K., E.I.G., and E.S.-N. performed research; J.Z. contributed unpublished reagents/analytic tools; B.S.M., A.K., E.I.G., and S.D. analyzed data; B.S.M., A.K., E.I.G., J.Z., and S.D. wrote the paper.

This work was supported by the Canadian Institutes of Health Reserch (CIHR Grant MOP-14828 to S.D.). B.S.M. was funded by the Brazilian PhD Sandwich Program (Coordenação de Aperfeiçoamento de Pessoal de Nível Superior, CAPES). A.K. was supported by postdoctoral fellowships from the CIHR and the CIHR Neuroinflammation Training Program. E.I.G. was funded by a studentship from the MS Society of Canada. We thank Margaret Attiwell for help with the illustrations and Ourania Tsatas and Laura Curran for technical assistance. called Wallerian degeneration (WD). Macrophages and Schwann cells play an important role during WD (Stoll et al., 1989; Brück, 1997; Martini et al., 2008; Bastien and Lacroix, 2014; Mietto et al., 2015). Almost immediately after axotomy, Schwann cells begin to express proinflammatory cytokines and chemokines, including TNF, IL- $1 \alpha$, IL-1 $\beta$, CCL2/MCP-1, and CCL3/MIP- $1 \alpha$ (Toews et

The authors declare no competing financial interests.

Correspondence should be addressed to Dr. Samuel David, Centre for Research in Neuroscience, The Research Institute of the McGill University Health Centre, Livingston Hall, Room L7-210, 1650 Cedar Ave., Montreal, Quebec, Canada, H3G 1A4. E-mail: sam.david@mcgill.ca.

DOI:10.1523/JNEUROSCI.2119-15.2015

Copyright $\odot 2015$ the authors $\quad 0270-6474 / 15 / 3516431-12 \$ 15.00 / 0$ 
al., 1998; Taskinen and Röyttä, 2000; Shamash et al., 2002; Perrin et al., 2005; Martini et al., 2008). The expression of these molecules triggers the recruitment and activation of macrophages from the peripheral circulation (Taskinen and Röyttä, 1997; Perrin et al., 2005) and the proliferation and activation of resident macrophages (Shen et al., 2000; Mueller et al., 2001; Mueller et al., 2003). Macrophages come in close contact with degenerated axons within the bands of Büngner and play an important role in phagocytosing axonal and myelin debris, a role that is initially performed by Schwann cells before the entry of peripheral macrophages (Stoll et al., 1989; Griffin et al., 1992; Brück et al., 1996; Fry et al., 2007). The removal of degenerating axons and myelin by macrophages is crucial for axon regeneration to proceed because peripheral myelin contains several axonal growth inhibitors (David et al., 1995; Filbin, 2003). A proinflammatory response induced by TLR signaling and involving TNF and IL-1 is required for effective WD and subsequent axon regeneration (Boivin et al., 2007; Nadeau et al., 2011; Mietto et al., 2013).

WD in peripheral nerves is rapid and well timed. The early proinflammatory response that occurs during the first 2 weeks that is needed for phagocytosis of degenerating material from the distal nerve segment is followed rapidly by resolution of inflammation, axon regeneration, and remyelination. We and others have reported that proinflammatory cytokines such as IL-1 $\beta$ and TNF are expressed after sciatic nerve crush injury and are accompanied by the expression of the anti-inflammatory cytokine IL-10 (Gillen et al., 1998; Be'eri et al., 1998; Shamash et al., 2002; Perrin et al., 2005; Bastien and Lacroix, 2014). What role IL-10 plays in the timely resolution of inflammation and axon regeneration is not entirely clear.

In the present study, we characterized the expression of IL-10 after sciatic nerve injury in mice and the cell types that produce it. We assessed the role of IL-10 in WD using IL-10-null mice. In particular, we assessed its effects on macrophage responses such as recruitment, differentiation phenotypes, and clearance out of the nerve during WD. A chemokine/cytokine array analysis was also performed on injured nerves from both genotypes to assess IL-10-mediated regulation of expression of other cytokines. In addition, bone-marrow-derived macrophages from WT and IL-10 mice were examined in in vitro assays for their response to LPS stimulation and myelin phagocytosis. We also assessed the effects of the lack of IL-10 on axon regeneration and recovery of motor and sensory function.

\section{Materials and Methods}

Sciatic nerve crush injury

All animal procedures were approved by the McGill University Animal Care Committee and followed the guidelines of the Canadian Council on Animal Care. Eight- to 10-week-old male C57BL/6 and IL-10-null mice on the same background (Jackson Laboratory) were used for all in vivo experiments. Animals were housed under a $12 \mathrm{~h}$ light/dark cycle with food and water ad libitum. Animals were deeply anesthetized with intraperitoneal injections of ketamine/xylazine/acepromazine (50/5/1 mg/ $\mathrm{kg}$ ). A small incision was made on the skin and the right sciatic nerve was exposed and crushed at the midthigh level for $30 \mathrm{~s}$ using a fine forceps (\#5C; Fine Science Tools) as described previously (Mietto et al., 2013). The skin was closed with 5-0 nylon sutures.

\section{Immunofluorescence labeling and confocal microscopy}

After varying lengths of time after nerve crush injury, mice were deeply anesthetized with ketamine/xylazine/acepromazine (50/5/1 $\mathrm{mg} / \mathrm{kg}$ ) and perfused via the heart with $4 \%$ paraformaldehyde in $0.1 \mathrm{M}$ PBS, pH 7.4. The left (control) and right (injured) nerve segments were dissected and fixed for another $2 \mathrm{~h}$ in the same fixative solution ( $n=4-5$ mice per group for each time point). The injured nerve was composed of the proximal stump, the lesion site, and the distal portion, whereas the control nerve segment consisted of the same length of nerve taken at the same level from the contralateral leg. After cryoprotection, tissue was sectioned longitudinally at $10 \mu \mathrm{m}$ thickness. To block nonspecific binding of antibodies, tissue sections were incubated in blocking solution (5\% normal serum plus $2 \%$ ovalbumin in PBS with $0.3 \%$ Triton $\mathrm{X}-100$ ) at room temperature for at least $1 \mathrm{~h}$. Sections were then incubated overnight at $4^{\circ} \mathrm{C}$ with primary antibodies: goat anti-IL-10 (1:50; Santa Cruz Biotechnology, M-18, sc-1783), rat anti-CD11b monoclonal (1:200; AbD Serotec, MCA711); rabbit anti-Iba1 (1:400; Wako, 019-19741); rat anti-CD86 monoclonal (1:100; BD PharMingen, 550542), goat anti-CD206 (1: 200; Santa Cruz Biotechnology, C-20, sc-34577); goat anti-CD16/32 (1:200; R\&D Systems, AF1460), rabbit anti-CD163 (1:200; Santa Cruz Biotechnology, M-96, sc-33560); goat anti-arginase-1 (1:200; Santa Cruz Biotechnology, V-20, sc-18354); and rabbit anti-GAP-43 polyclonal (1:500; Millipore, AB5220). Specific staining for iNOS could not be obtained with three different antibodies and different postfixation protocols. Sections were then rinsed in PBS with $0.05 \%$ Tween 20 (PBS-T) and incubated with fluorescence-conjugated secondary antibodies. For IL-10, we used biotinylated anti-goat 1:400 (1 h) followed by streptavidin-conjugated fluorescein 1:700 (1 h; both from Jackson Immuno Research). For other primary antibodies, one of the following was used: donkey anti-rat Alexa Fluor 647 1:500 (2 h), goat anti-rabbit Alexa Fluor 647 1:500 (2 h), donkey anti-rat Alexa Fluor 488 1:500 (2 h), donkey anti-goat Alexa Fluor 568 1:500 (2 h), donkey anti-rabbit Alexa Fluor 568 1:500 (2 h), donkey anti-goat Alexa Fluor 488 1:500 (2 h), or donkey anti-rabbit Alexa Fluor 488 1:500 (2 h) (all from Life Technologies). Tissue sections were washed in PBS-T and coverslipped in DAPI containing mounting medium (Vector Laboratories) and examined with a confocal laser scanning microscope (FluoView FV1000; Olympus) and micrographs taken at a distance of $\sim 3$ $\mathrm{mm}$ distal to the injury using FV10-ASW 3.0 software (Olympus).

\section{Bone marrow-derived macrophage (BMDM) culture and} chemokine/cytokine ELISA

Adult female WT and IL-10-null BALB/c mice were killed using $\mathrm{CO}_{2}$ and the bone marrow from the long bones of the lower limb was flushed with culture medium. Cells were centrifuged at $1000 \mathrm{rpm}$ for $10 \mathrm{~min}$ and then resuspended and plated onto polystyrene non-tissue-culture-treated $\mathrm{Pe}$ tri dishes. Cells were grown in RPMI culture medium supplemented with $\mathrm{L}$-cell medium at $37^{\circ} \mathrm{C}$ and $5 \% \mathrm{CO}_{2}$ for $7 \mathrm{~d}$ before use in the assays. Cells were removed by $0.02 \%$ EDTA in PBS and plated at a density of $1 \times 10^{6}$ cells/well in 6-well plates. Cells were then left to adhere for $2 \mathrm{~d}$ at $37^{\circ} \mathrm{C}$ and $5 \% \mathrm{CO}_{2}$ before they were used.

To assess the protein levels of different chemokines and cytokines, the BMDM from WT and IL-10-null mice, obtained as described above, were cultured for $5 \mathrm{~h}$ in medium without L-cell-conditioned medium, incubated for $24 \mathrm{~h}$ in culture medium with or without myelin $(50 \mu \mathrm{g} / \mathrm{ml})$ for $24 \mathrm{~h}$, and then incubated for another $24 \mathrm{~h}$ with LPS $(10 \mathrm{ng} / \mathrm{ml})$. The supernatant was then removed and stored at $-20^{\circ} \mathrm{C}$ until use. The cell supernatants were assayed using a multianalyte ELISA array following the product manual instructions (MEM-005A; SuperArray Biosciences) for the cytokines and chemokines IL-6, TNF, MCP-1/CCL2, MIP-1 $\alpha$ / CCL3, and MIP-1 $\beta /$ CCL4 $(n=3)$. Expression of cytokines and chemokines is presented as the fold increase above control levels observed for cells incubated with cell culture medium alone.

\section{Quantitative RT-PCR}

At defined time points after nerve crush, animals under anesthesia were perfused with cold PBS and the distal segments $(\sim 5-7 \mathrm{~mm})$ from control and injured nerves were dissected, snap frozen in liquid nitrogen, and stored at $-80^{\circ} \mathrm{C}$ until use. Two nerves were pooled for each sample and then 3 such samples $(n=3)$ were taken for the uninjured and $1 \mathrm{~d}$ postinjury time points and 4 samples $(n=4)$ for the 7 and $14 \mathrm{~d}$ postinjury time points. Total RNA was isolated from sciatic nerves using RNeasy Mini Lipid Tissue kit (Qiagen) following the manufacturer's instructions. cDNA was reverse transcribed with the Qiagen Omniscript Kit (catalog \#205110) and amplified in an ABI 
OneStep cycler (Applied Biosystems) using specific primer pairs for IL-10 (forward: 5' ACA GCC GGG AAG ACA ATA AC 3' and reverse: 5' CAG CTG GTC CTT TGT TTG AAA G 3'); peptidylprolyl isomerase (PPIA) (forward: 5' ATG TGC CAG GGT GGT GACTTT A-3 and reverse: 5' TGT GTTTGGTCC AGC ATT TGC C-3) used as the housekeeping gene. All PCRs were done in triplicate and the levels of PPIA were used to normalize results. The results were quantified using the $\Delta \Delta \mathrm{CT}$ method following standardization relative to the internal control gene (Livak and Schmittgen, 2001).

\section{Gene expression array and $q R T-P C R$}

The distal portion of the crushed sciatic nerves were obtained $24 \mathrm{~h}$ after injury and RNA extracted as described above, followed by reverse transcription with the $\mathrm{RT}^{2}$ first strand kit (Qiagen). The $\mathrm{RT}^{2}$ profiler cytokine array (PAMM-150Z) was performed according to the manufacturer's instructions (Qiagen) ( $n=3-4$ samples of 2 pooled nerves per group). Array results were analyzed using the software tools provided by the manufacturer. Only genes significantly upregulated or downregulated were selected.

\section{Measurement of axon regeneration}

Three days after crush injury, mice were perfused with $4 \%$ paraformaldehyde and the nerve prepared for cryostat sectioning. Serial sections (12 $\mu \mathrm{m}$ thickness) of each crushed nerve were cut and four sections were taken per slide on seven slides. On each slide, the adjacent sections were seven sections (i.e., $84 \mu \mathrm{m}$ ) apart. One slide was taken for GAP-43 labeling for each animal. The sections on the slide represent serial sections through the entire nerve. From our previous experience with assessing axon regeneration after sciatic nerve crush injury (López-Vales et al., 2008), we found that $3 \mathrm{~d}$ after crush injury was the best time because, by $7 \mathrm{~d}$, the axons had regenerated into the various branches of the sciatic nerve and past the common trunk of the nerve in the thigh. A $2 \mathrm{~d}$ time point has been used previously (Ma et al., 2011). To identify the site of crush injury, the sections were double-labeled with anti-CD11b to visualize macrophages. The CD11b labeling showed intense staining at the injury site. The axon length measurements were made from the midpoint of the CD11b-stained region. The length of the GAP-43 labeling was quantified using a motorized stage with micrometer distance display. Quantification was done on 4 WT and 3 IL-10-null mice and data were analyzed with the Mann-Whitney test.

\section{Functional analysis}

Motor recovery. Two weeks before lesion and at 7, 14, 21, and $28 \mathrm{~d}$ after crush injury, the hindpaws were inked and mice allowed to walk down a 40-cm-long track (WT and IL-10-null; $n=5-6$ ). The sciatic functional index (SFI) was calculated from the footprints according to the formula established by Inserra et al. (1998). Briefly, the SFI was analyzed by dividing the distance between the first and fifth toes with the distance between the tip of the third digit and the posterior end of the foot print, as we described previously (López-Vales et al., 2008). The normal, uninjured SFI value is $\sim-10$, which is markedly reduced to -100 after injury and followed by a gradual return to the normal values with nerve regeneration.

Sensory recovery. Mice were habituated to the testing environment for $2 \mathrm{~d}$ before baseline testing. Paw-withdrawal thresholds were measured to assess mechanical sensitivity with calibrated von Frey fibers (Stoelting). Animals (WT and IL-10-null; $n=5$ ) were placed on an elevated metal mesh and covered with small Plexiglas chambers $(9 \times 5 \times 5 \mathrm{~cm}$ high $)$ for at least $1 \mathrm{~h}$ for habituation before testing. von Frey fibers ranging from 0.008 to $1.40 \mathrm{~g}$ of force were applied to the plantar surface of the hindpaw until they bent. The threshold force required to elicit $50 \%$ withdrawal of the paw was determined using the "up-down method" described previously (Chaplan et al., 1994). One week before sciatic nerve crush and once a week up to $28 \mathrm{~d}$ after injury, animals of both genotypes were tested to score their response to von Frey hairs.

\section{Statistical analysis}

Graphics were generated using the Prism version 6.0 software (GraphPad Software). One-way or two-way ANOVA followed by Sidak's or Bonfer- roni multiple test comparisons or the Mann-Whitney test were used as indicated. Differences were considered significant at $p \leq 0.05$.

\section{Results \\ Macrophages are the main cellular source of IL-10 during WD}

We first assessed the pattern of IL-10 expression in the distal segment of the mouse sciatic nerve after crush injury. IL-10 is not expressed in the uninjured sciatic nerves, but is upregulated in the distal segment after nerve crush (Fig. $1 A, B$ ). The mRNA levels of IL-10 began to increase starting at day 1 after injury and reached a peak of expression at day 7 (5.6-fold, $p<$ $0.0001)$ and then returned to basal levels at day $14(\sim 0.9$-fold, $p>0.05 ; n=3-4$ pooled samples per time point per group). At the protein level, IL-10 expression was detected in cells in the distal segment of the nerve by immunofluorescence for more prolonged periods of time of up to $21 \mathrm{~d}$ after injury. IL-10-positive cells were not present in uninjured control nerves but increased significantly in numbers by $\sim 2.8$-fold in the first 2-3 weeks after injury compared with day 3 (Figs. $1 B$; $n=3$ mice per group). Their numbers were similar at days 14 and 21 (Fig. 1B). Double immunofluorescence labeling revealed that, at 3,14 , and $21 \mathrm{~d}$ after injury, the majority of the cells $(93 \%, 77 \%$, and $85 \%$, respectively) in the distal nerve segment expressing IL-10 were CD11b ${ }^{+}$macrophages (Fig. $1 C-F ; n=3$ mice per group) that were widely distributed in the injured nerve. The small number of CD11b-negative cells that express IL-10 (7-23\%) are likely to be Schwann cells and fibroblasts as described previously (Be'eri et al., 1998). At 14 and $21 \mathrm{~d}$ after injury, the IL-10-positive macrophages had a foamy morphology (Fig. $1 E, F$ ) compared with cells at day 3 (Fig. 1D), indicating that they were at the end stage of myelin degradation.

\section{Increased numbers of macrophages after nerve injury in IL-10-null mice}

Macrophage numbers gradually increase during WD and this accumulation is mediated by proinflammatory chemokines and cytokines (Subang and Richardson, 2001; Perrin et al., 2005; Nadeau et al., 2011). To assess whether the antiinflammatory cytokine IL-10 regulates this inflammatory response, we assessed differences in macrophage numbers in WT and IL-10-null mice after sciatic nerve crush injury. In WT mice, macrophage numbers increased 4-fold from day 1 to 14 after injury. Thereafter, the numbers dropped by $29 \%$ by day 21 , which reflects the clearance of these cells from the nerve and the eventual resolution of inflammation. Interestingly, in the absence of IL-10, macrophage numbers were increased by $57 \%$ at day 3 and by $25 \%$ at day 14 after injury compared with WT nerves (Fig. $2 A ; n=4-5$ mice for each time point). Moreover, whereas macrophage numbers in WT mice begin to decline at day 21 , their numbers remain elevated in IL-10-null mice, being 51\% higher than WT injured nerves. Based on the data shown in Figure $1, B$ and $C, \sim 30$ cells/0.1 $\mathrm{mm}^{2}$ would be IL- $10^{+} / \mathrm{CD} 11 \mathrm{~b}{ }^{+}$macrophages at day 14 . Figure $2 A$ shows that there are $\sim 130$ macrophages $/ 0.1 \mathrm{~mm}^{2}$ at day 14 , of which only 30 cells are likely to be IL- $10^{+}$. Because this number of IL- $10^{+}$macrophages does not change between days 14 and 21 (Fig. 1C), the marked drop of $29 \%$ in the number of CD11b ${ }^{+}$cells between 14 and $21 \mathrm{~d}$ in WT mice is likely due to reduction in the IL-10-negative population. These data suggest that IL-10 may control the influx of macrophages during the early phase at $3 \mathrm{~d}$ after injury and may also 

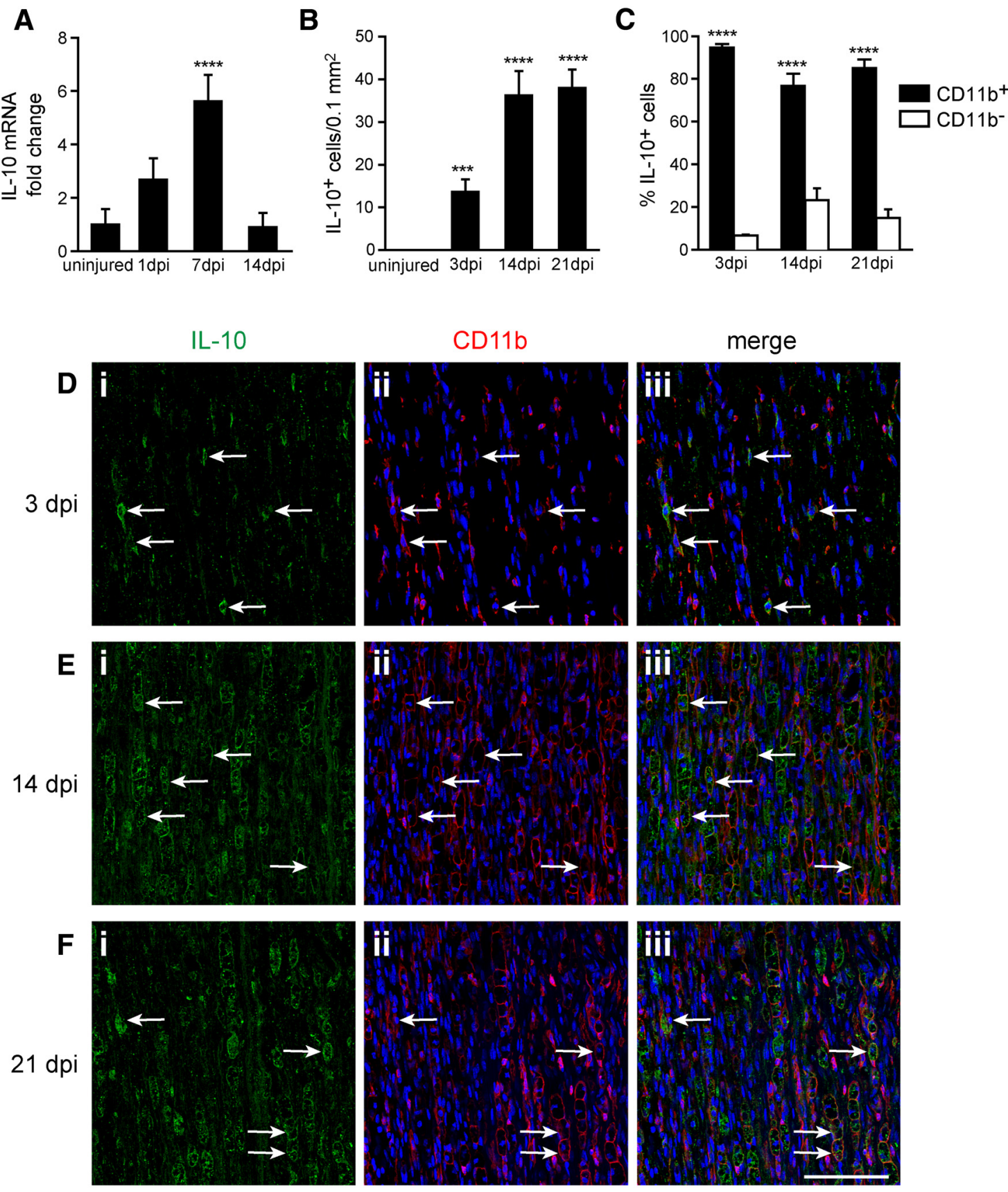

Figure 1. Changes in expression of IL-10 in the distal segment of the sciatic nerve after crush injury. $\boldsymbol{A}$, Graph showing the fold change in IL-10 mRNA levels at different days postinjury (dpi) compared with uninjured nerve, detected by qRT-PCR. Note the gradual increase in expression over the first $7 \mathrm{~d} . n=3-4$ samples of 2 pooled nerves per time point; mean \pm SEM; ${ }^{* * * *} p<0.0001$ from uninjured nerve. $\boldsymbol{B}$, Graph showing changes in the number of $\mathrm{IL}-10^{+}$cells detected by immunofluoresence labeling of the sciatic nerve at a distance of $\sim 3 \mathrm{~mm}$ distal to the injury. $n=3$ per time point; mean \pm SEM; ${ }^{* * *} p<0.001,{ }^{* * * *} p<0.0001$ from uninjured nerve. C, Quantification of double-immunofluoresence labeling of the nerve with antibodies against IL-10 and CD11b. Note that the vast majority of the IL- $10^{+}$cells in the distal nerve segment are CD11b ${ }^{+}$macrophages. Counts were done at a distance of $\sim 3 \mathrm{~mm}$ distal to the injury. $n=3$ per time point; mean $\pm \mathrm{SEM}^{* * * *} p<0.001,{ }^{* * * *} p<0.0001$ compared with $\mathrm{CD}^{*} 1 \mathrm{~b}^{-}$cells in each group. $\boldsymbol{D}-\boldsymbol{F}$, Double-immunofluorescence labeling for IL-10 (i) and CD11b (ii), and merged images (iii) of the nerve at $3(\boldsymbol{D}), 14(\boldsymbol{E})$, and $21(\boldsymbol{F})$ dpi. Note the increase in IL-10 labeling over time after injury and the presence of IL-10 labeling in foamy phagocytic macrophages at the later time point $(\boldsymbol{E}, \boldsymbol{F})$. Arrows point to double-labeled cells. Scale bar, $100 \mu \mathrm{m}$.

play a role in promoting their efflux after the period of WD during the recovery phase at day 21.

IL-10-null macrophages do not switch off expression of proinflammatory molecules after myelin phagocytosis in vitro

Myelin breakdown and phagocytosis occurs during WD in the first $10 \mathrm{~d}$ after nerve injury. Several in vitro studies have re- ported that myelin phagocytosis by activated macrophages decreases the expression of proinflammatory cytokines (Boven et al., 2006; van Rossum et al., 2008; Kroner et al., 2014). We therefore sought to assess how macrophages in IL-10-null nerves respond to myelin phagocytosis. To assess this, cultures of BMDM from WT and IL-10-null mice were incubated with myelin and LPS, as indicated in the Materials and Methods section. Culture supernatants were collected and expression of 


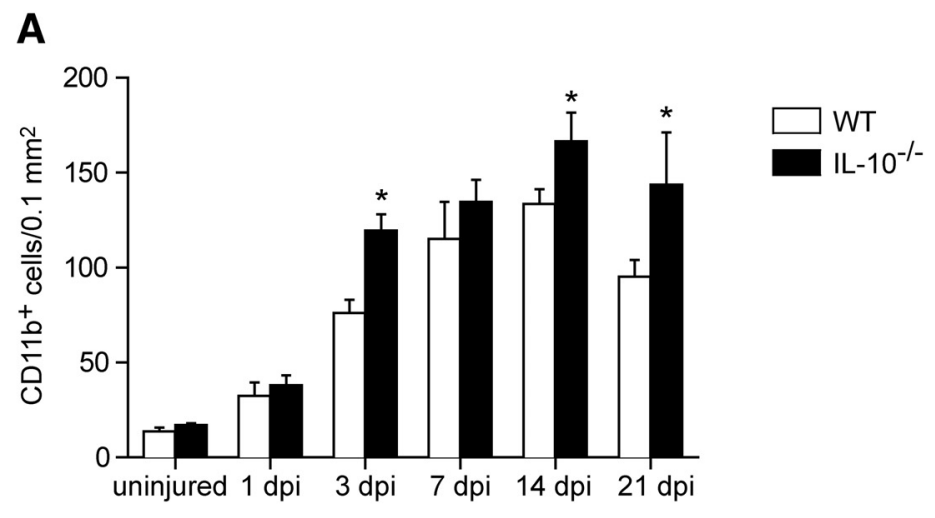

B

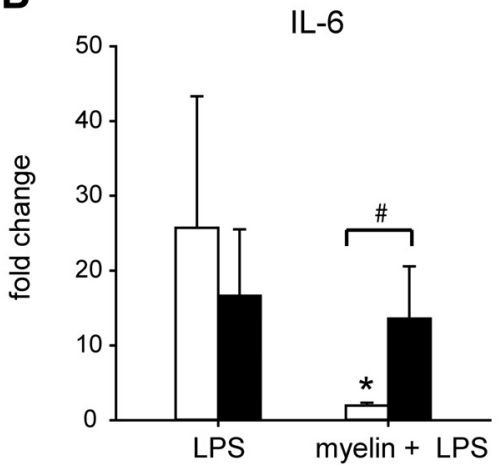

D

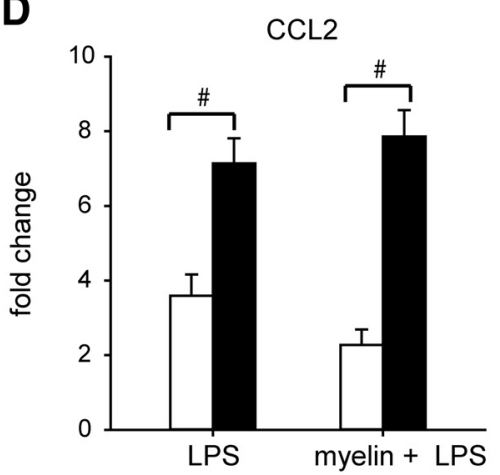

C

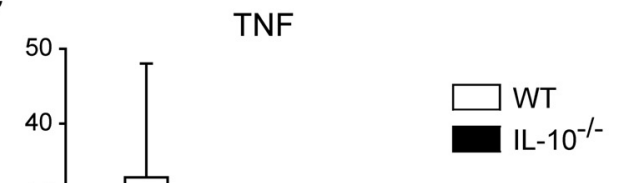

E

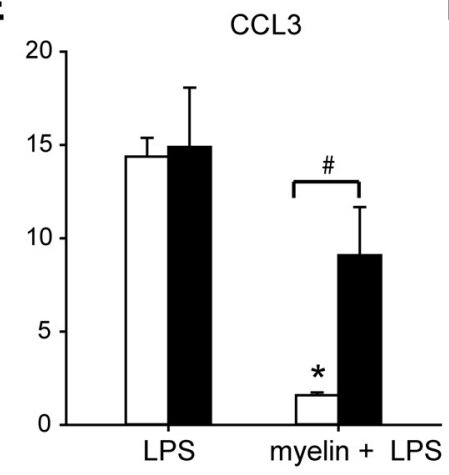

$\mathbf{F}$

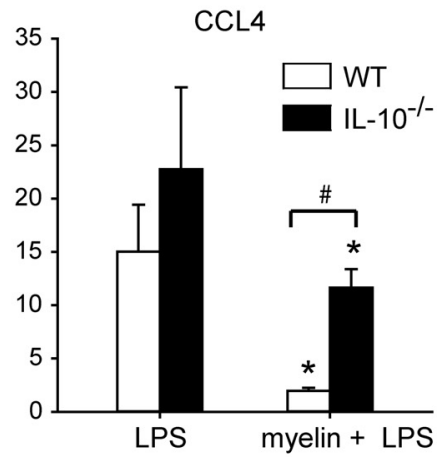

Figure 2. Changes in macrophage numbers in injured nerve and response of BMDM to myelin phagocytosis. $A$, Graph showing changes in the number of CD11b ${ }^{+}$macrophages in the uninjured and injured distal nerve segment at different times after crush injury in WT and IL-10-null (IL-10 ${ }^{-/}$) mice. Note the significant increase in macrophages in the nerves of IL-10-null mice compared with WT mice at 3,14 , and $21 \mathrm{~d}$ postinjury (dpi). $n=4-5$ nerves per time point per group; mean \pm SEM; ${ }^{*} p<0.05$. $\boldsymbol{B}-\boldsymbol{F}$, Graphs showing response of BMDM from WT and IL-10 ${ }^{-1-}$ mice to LPS stimulation with and without myelin phagocytosis. Note that myelin phagocytosis (myelin + LPS) by WT BMDM reduces the expression of TNF, IL-6, $C C L 3$, and $C C L 4 . n=3$; mean $\pm S D ;{ }^{*} p<0.05$. In contrast, myelin phagocytosis by BMDM from IL-10 ${ }^{-1-}$ mice does not significantly reduce expression of these molecules, except for CCL4, compared with stimulation with LPS alone. Cytokine and chemokine levels were significantly higher in IL $10^{-l-}$ cells after myelin + LPS compared with WT cells. \#p $<0.05$. Note also the 3 -fold increase in CCL2 expression in LPS-stimulated IL-10 ${ }^{-1-}$ cells compared with WT cells. \#p $<0.05$.

cytokines and chemokines assayed by ELISA $(n=3$ samples per group). As expected, incubation with LPS alone increased by several fold the production of proinflammatory cytokines IL- 6 and TNF and the chemokines CCL2, CCL3, and CCL4 by both WT and IL-10-null macrophages. With the exception of CCL2, which was significantly higher in IL- $10^{-1-}$ cells, there was no significant difference between genotypes, although TNF showed a great deal of variance in WT cultures (Fig $2 B-$ $F)$. Importantly, LPS-treated BMDM from WT mice that phagocytosed myelin showed a marked reduction in expression of proinflammatory chemokines and cytokines compared with LPS stimulation alone, with the exception of CCL2 (Fig.
$2 B-F)$. In contrast, myelin phagocytosis by BMDM from IL10-null mice failed to downregulate expression of these proinflammatory chemokines and cytokines, except for CCL4. Nevertheless, CCL4 in IL-10 ${ }^{-1-}$ cells treated with myelin and LPS was still 6.5-fold higher than in WT cells (Fig. $2 B-F$ ). Note that, with myelin phagocytosis, the expression of all five proinflammatory molecules was significantly higher in IL-10-null cells than in WT cells (4-fold higher for IL-6, TNF, and CCL2; 3.5-fold for CCL3; and 6.5-fold higher for CCL4). These data support the notion that increased and prolonged macrophage accumulation after nerve injury in IL-10-null mice may be related, at least in part, to their inability to downregulate ex- 
A

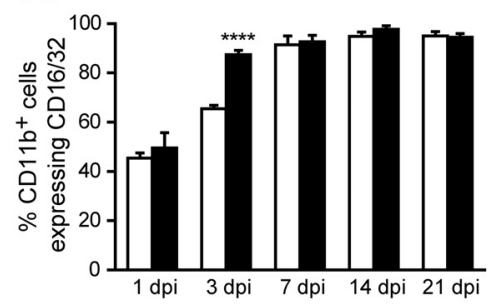

C

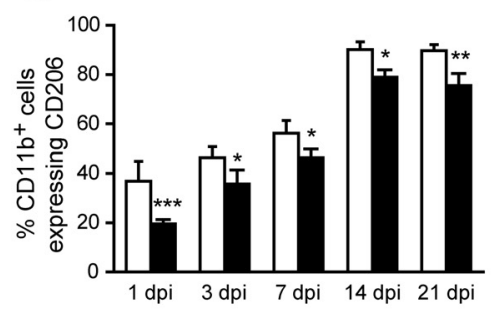

$\mathbf{F}$

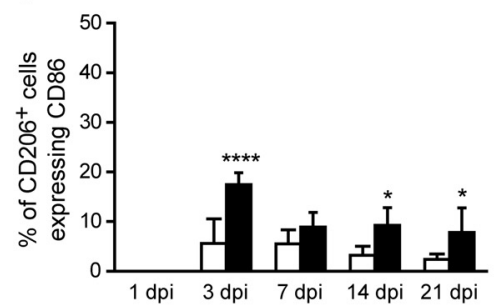

B

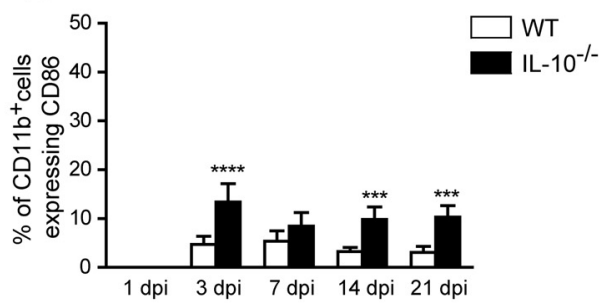

E
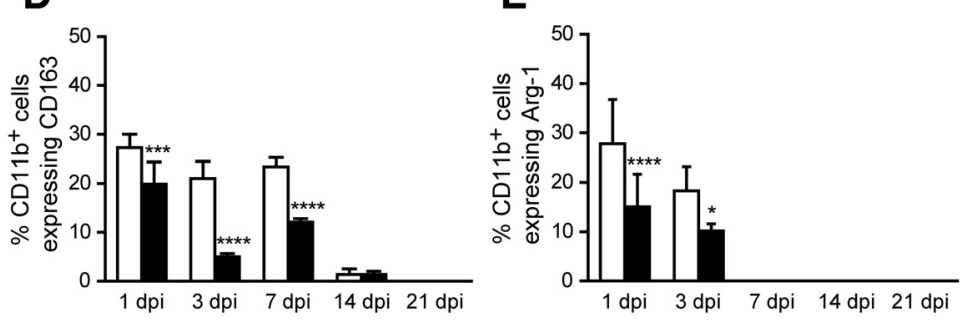

G

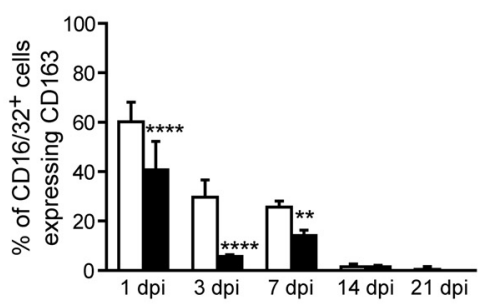

Figure 3. Changes in expression of macrophage markers in WT and IL-10 ${ }^{-/-}$nerves at different times after crush injury. Shown are changes in proinflammatory M1 markers $C D 16 / 32(\boldsymbol{A})$, $\mathrm{CD} 86$ $(\boldsymbol{B})$, and anti-inflammatory M2 markers CD206 (C), CD163 (D), and Arg-1 (E). Note the increase in CD16/32 and CD86 (A, B) and decrease in CD206 and Arg-1 (C-E) expression in IL-10-null nerves compared with WT nerves. Double labeling for CD206 and CD86 (F) and CD16/32 and CD163 (G) show that, in IL-10-null nerves, a greater number of CD206 ${ }^{+}$macrophages also express the proinflammatory M1 marker CD86 $(\boldsymbol{F})$ and fewer CD16/32 ${ }^{+}$macrophages express the anti-inflammatory M2 marker CD163 (G) at various times after injury. $n=4-5$ mice per time point per group; mean \pm SEM; ${ }^{* *} p<0.01,{ }^{* * *} p<0.001,{ }^{* * * *} p<0.0001$.

pression of proinflammatory molecules in response to myelin phagocytosis.

\section{Lack of IL-10 influences macrophage phenotype}

Macrophages stimulated in vitro with LPS or IL-4 differentiate to a proinflammatory, cytotoxic phenotype or to an antiinflammatory, pro-repair phenotype, respectively, and are referred to as M1 and M2 macrophages that exist along a continuum (Gordon and Taylor, 2005; Mantovani and Locati, 2009; David and Kroner, 2011; Murray et al., 2014). A recent reassessment of this classification suggested calling these cells by the stimuli by which they are activated in vitro; for example, M(LPS) for LPS-activated cells and M(IL-4) for IL-4-activated cells (Murray et al., 2014). However, this is difficult to do in vivo because multiple stimuli are likely to act on macrophages (David et al., 2015). However, the expression of CD86, CD16/32, and iNOS co-localizes to proinflammatory M1 cells and the expression of CD206, CD163, and arginase 1 (Arg1) co-localizes to antiinflammatory M2 cells in vivo in the spinal cord (Kigerl et al., 2009; Kroner et al., 2014) and peripheral nerve (Ydens et al., 2012; Chen et al., 2015; Niemi et al., 2015). We therefore assessed the role of IL-10 in modulating the expression of such macrophage differentiation markers during the period of WD and regeneration after sciatic nerve crush injury $(n=4-5$ mice per time point per group). CD16/32 is expressed robustly in $\sim 90 \%$ of the macrophages $7 \mathrm{~d}$ after injury; at earlier time points, 1 and $3 \mathrm{~d}$ after injury, it is expressed in $45 \%$ and $65 \%$ of macrophages (Fig. $3 A$ ).
The lack of IL-10 sped the rate of increase of CD16/32 to maximal levels by day 3 (Figs. 3A, 4). Although CD86 is expressed in only a small subpopulation of $\sim 5 \%$ of macrophages in WT animals at all the time points studied after nerve injury, their numbers in IL-10-null injured nerves increased $\sim 3$-fold higher than WT nerves at 3, 14, and $21 \mathrm{~d}$ after injury (Fig. 3B, 4). Expression of NOS 2 mRNA was not detected by qRT-PCR and three iNOS antibodies and different fixation protocols tested gave nonspecific labeling. Lack of IL-10 also had an effect on the expression of three markers associated with anti-inflammatory M2 [or M(IL4)-like] macrophages (CD206, CD163, and Arg-1). The expression of CD206 in WT nerves increased gradually after injury, from $\sim 37 \%$ at $1 \mathrm{~d}$ to $90 \%$ at 14 and $21 \mathrm{~d}$ (Fig. $3 C$ ). In injured nerves from IL-10-null mice, the number of $\mathrm{CD}_{20}{ }^{+}$macrophages was significantly reduced at all time points, being reduced by $47 \%, 23 \%, 17 \%, 12 \%$, and $16 \%$ at days $1,3,7,14$, and 21 after injury, respectively (Figs. 3C, 5). CD163 was expressed in $\sim 20-$ $30 \%$ of macrophages in WT nerves in the first $7 \mathrm{~d}$ after injury. Their numbers were significantly reduced in IL-10-null mice, being $\sim 4$-fold lower at $3 \mathrm{~d}$ and $\sim 2$-fold lower at $7 \mathrm{~d}$ after injury (Figs. 3D, 5). Arginase- 1 was also expressed in $<30 \%$ of macrophages in WT nerves at 1 and $3 \mathrm{~d}$ after injury. Compared with WT nerves, IL-10-null nerves showed a 46\% reduction in Arg-1 ${ }^{+}$ macrophages at day 1 and a 44\% reduction at day 3 (Fig. $3 E$, $6 A, C)$. These results suggest that the lack of IL-10 leads to a greater shift toward a proinflammatory M1 [or M(LPS)-like] phenotype. Macrophages in vivo are influenced by multiple, often 


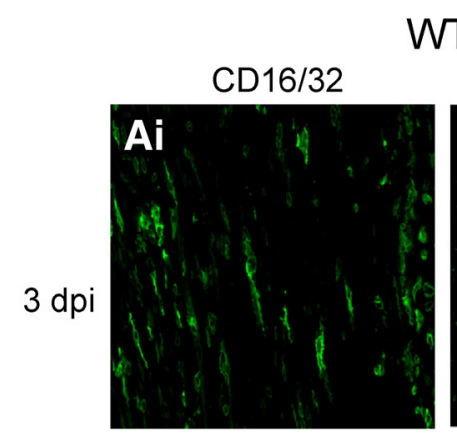

WT

IL10-/-
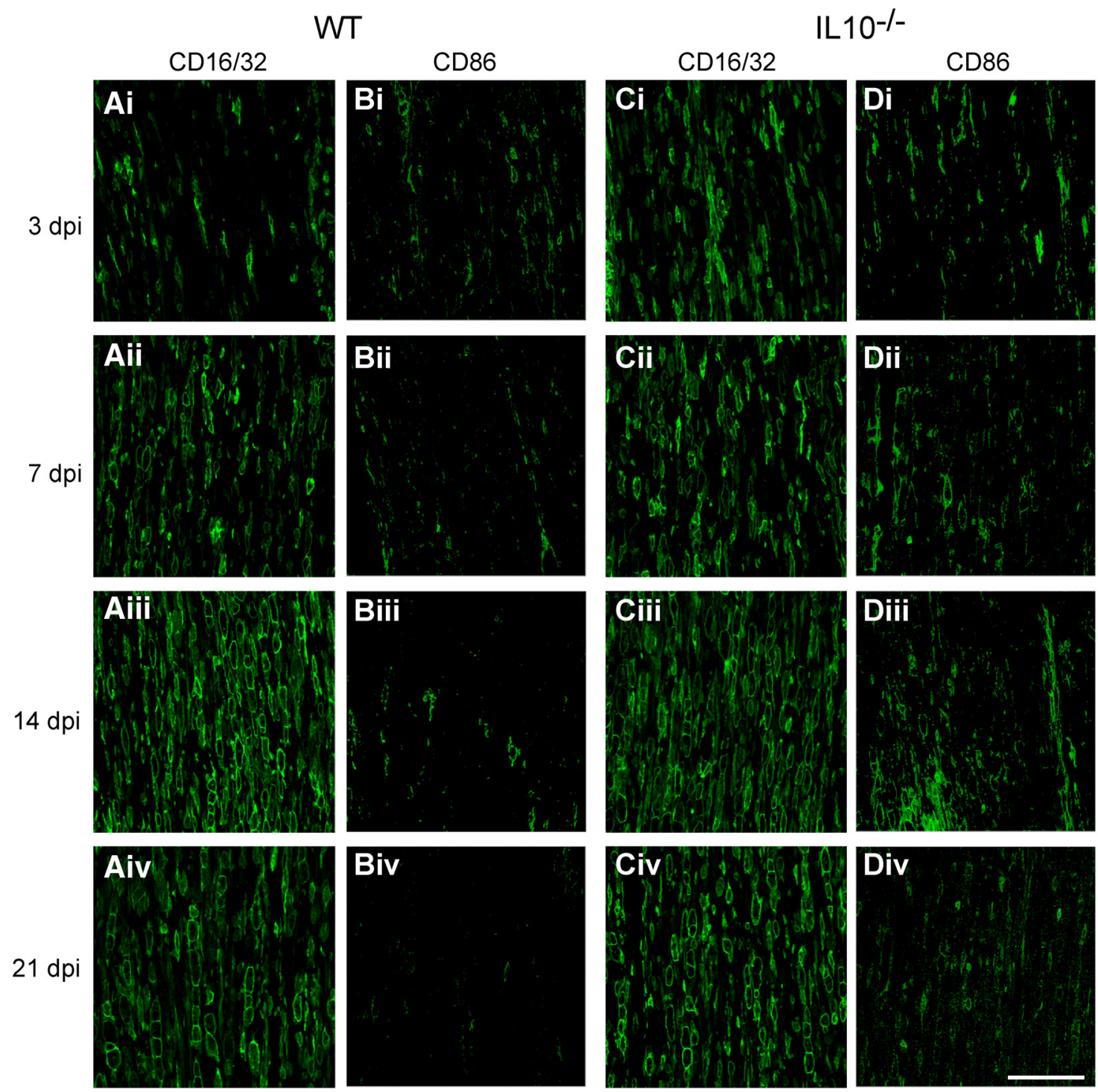

Figure 4. Immunofluorescence labeling of M1 macrophage markers CD16/32 in WT (A) and IL-10 ${ }^{-1-}(\boldsymbol{C})$ mice and CD86 in WT (B) and IL-10 $10^{-1-}(\boldsymbol{D})$ mice at 3 (i), 7 (ii), 14 (iii), and 21 (iv) days postinjury (dpi). CD16/32 expression increases rapidly in both WT (A) and IL-10 ${ }^{-I-}(C)$ nerves after injury. Note, however, the increased labeling at $3 \mathrm{~d}$ in IL-10 ${ }^{-1-}$ compared with WT nerves. In contrast, CD86 is expressed by very few cells in both WT (B) and IL-10 ${ }^{-1-}(\boldsymbol{D})$ nerves, but is increased in IL-10 ${ }^{-1-}$ compared with WT nerves. Scale bar, $100 \mu \mathrm{m}$.

antagonistic stimuli and, as a result, these cells can express overlapping phenotypic markers. As expected, some cells in the crushed nerves expressed both types of phenotypic markers. For example, at day 3, $\sim 5 \%$ or less of the $\mathrm{CD} 206^{+}$cells also expressed CD86 in injured WT nerves and this number increased 3 -fold in IL-10-null mice (Fig. 3F). Therefore, the lack of IL-10 results in increased percentage of $\mathrm{CD}^{2} 6^{+}$macrophages coexpressing CD86, which is associated with proinflammatory M1 [or M(LPS)-like] macrophages (Kroner et al., 2014). Similarly, at 1, 3 , and $7 \mathrm{~d}$, significantly fewer CD16/32 ${ }^{+}$cells in IL-10-null nerves coexpressed CD163, which is associated with antiinflammatory M2 [or M(IL-4)-like] macrophages compared with WT nerves (Fig. $3 G$ ), suggesting again a shift to a more proinflammatory phenotype.

Increased expression of proinflammatory chemokines and cytokines in the injured sciatic nerve in IL-10-null mice We also did a broad cytokine gene expression profiling using a PCR array for 84 cytokines, chemokines, and related genes $(n=$ 3-4 pooled samples per group). Comparisons were made be- tween WT and IL-10-null mice in the distal portion of the crushed sciatic nerve obtained $1 \mathrm{~d}$ after crush injury. Ten genes were statistically significantly increased between 2-fold and 5-fold (Fig. 6E). Three of the highest expressing genes included CCL2 ( 5-fold), CCL12 ( $\sim 4$-fold), and CXCL9 ( $>3$-fold). Increases of $\sim 2$-fold are also seen in IL- 6 and lymphotoxin $\beta$, a member of the TNF family. These results indicate an increase in a select set of chemokines and cytokines early after crush injury.

Functional recovery and axon regeneration are impaired after sciatic nerve injury in IL-10-null mice

Motor recovery

We assessed motor recovery after nerve injury using the SFI, which is a reliable method to estimate recovery of innervation of foot muscles. One week after injury in WT mice, the SFI decreased to a value of $\sim-100$, indicating total loss of motor innervation of the foot, and recovered to baseline after 4 weeks (Fig. $7 A$ ). In contrast, motor recovery in IL-10-null mice was impaired, with significantly lower SFI values at 3 and 4 weeks after injury (Fig. 7A). 


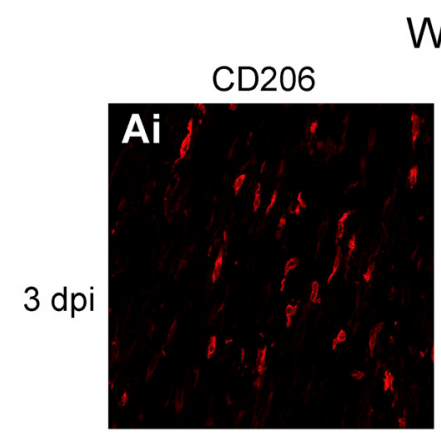

WT
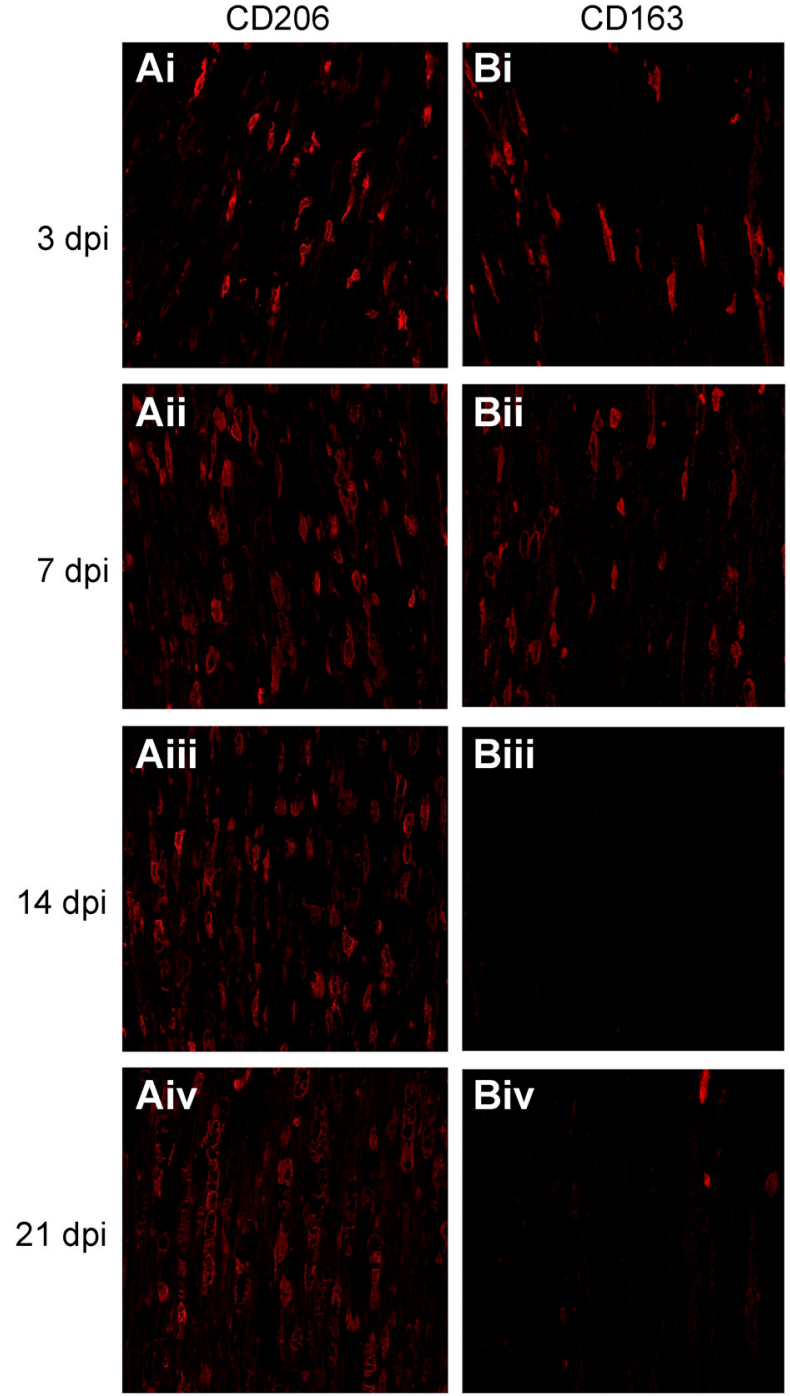
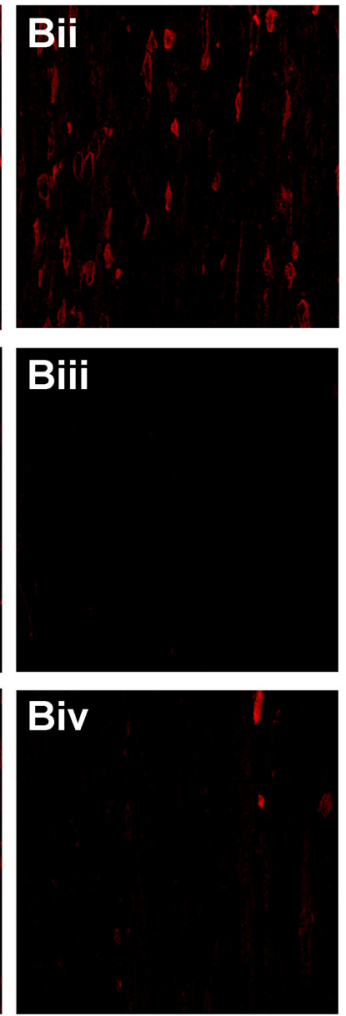
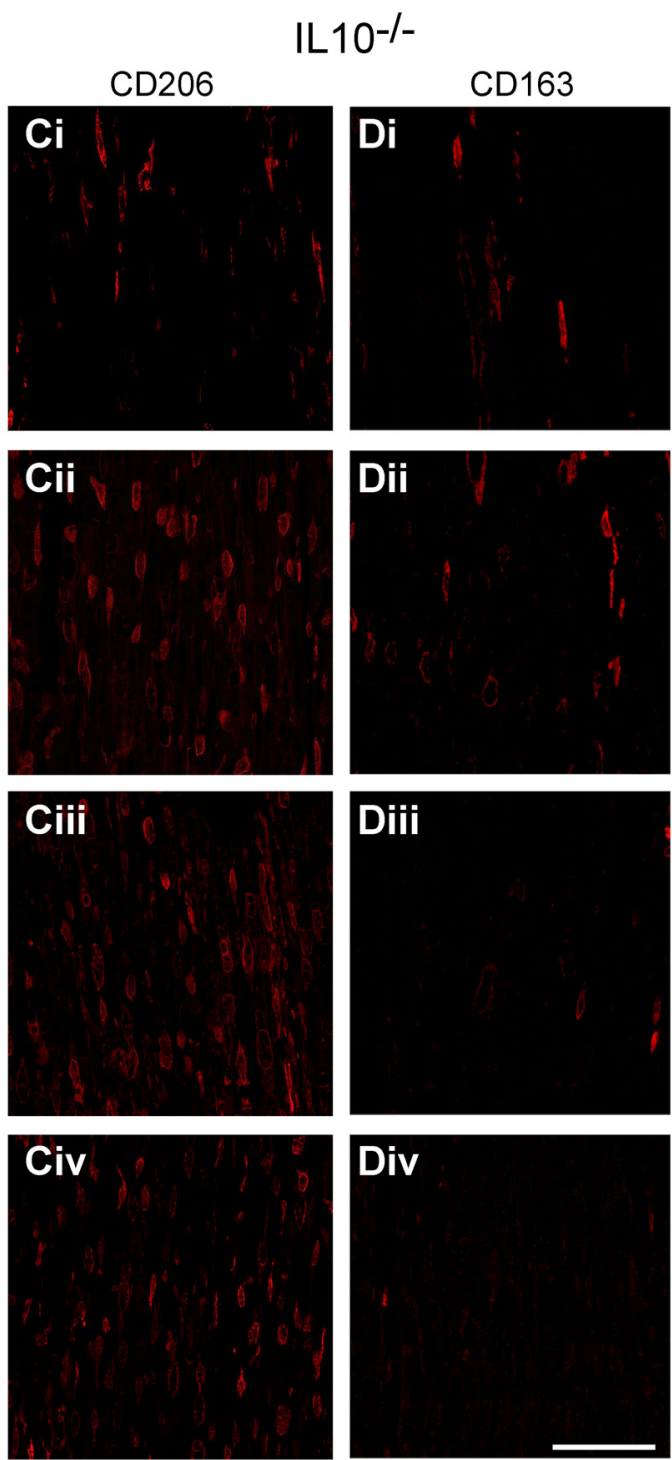
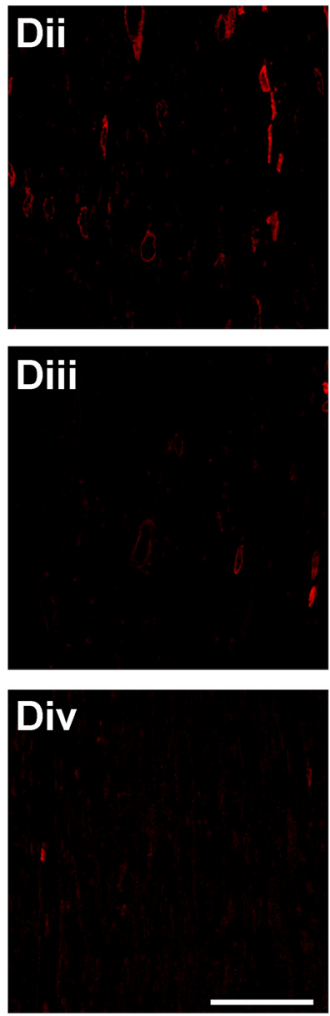

Figure 5. Immunofluorescence labeling of $\mathrm{M} 2$ macrophage markers $\mathrm{CD} 206$ in WT $(\boldsymbol{A})$ and IL-10 ${ }^{-1-}(\boldsymbol{C})$ mice and CD163 in WT (B) and IL-10 ${ }^{-1-}$ (D) mice at 3 (i), 7 (ii), 14 (iii), and 21 (iv) days postinjury (dpi). In both genotypes, the number of cells expressing CD206 increased with dpi, however, the labeling is more intense at the earlier time point of $3 \mathrm{~d}(\boldsymbol{A} \boldsymbol{i})$. The expression of $\mathrm{CD} 163$ decreased with time after injury in both WT (Bi-Biv) and IL-10 ${ }^{-1-}$ (Di-Div) nerves. Note, however, that the number of CD206 and CD163-labeled cells are lower in the IL-10 ${ }^{-1-}$ compared with the WT nerves. Scale bar, $100 \mu \mathrm{m}$.

Sensory recovery

Analysis of sensory function was measured by the pain reaction elicited after touch stimulus (von Frey hair). Mechanical allodynia was seen at all time points analyzed after injury in both WT and IL-10-null mice compared with uninjured mice (Fig. 7B). However, at day 28, WT mice start to show improvement, whereas IL-10-null mice continued to show the same level of mechanical allodynia on days 14 and 21 (Fig. 7B). These data indicate that lack of IL-10 leads to impairments of recovery of both motor and sensory function after sciatic nerve crush injury.

\section{Axon regeneration}

We also assessed axon regeneration after sciatic nerve crush injury in WT and IL-10-null mice. This was done on longitudinal cryostat sections of the nerve using immunofluorescence labeling for growth-associated protein 43 (GAP-43), which is highly expressed in regenerating axons. Axon regeneration was assessed $3 \mathrm{~d}$ after crush injury, when WT nerves showed regeneration for up to $4.3 \pm 0.7 \mathrm{~mm}$ beyond the crush injury site, which is con- sistent with previous reports (Ma et al., 2011). In contrast, in IL-10-null mice, axon regeneration was slower, reaching $3.3 \pm$ $0.2 \mathrm{~mm}$ distal to the injury (Fig. 7C,D). There were also significantly fewer GAP- $43^{+}$axons at $3 \mathrm{~mm}$ distal to the injury in IL-10-null nerves compared with WT nerves (WT $=7.6 \pm 0.6$; IL-10-null mice $=5.3 \pm 1.1$ axons/section; $p<0.04$ ).

\section{Discussion}

In the present study, we confirm and extend previous reports on the expression of IL-10 after peripheral nerve injury (Be'eri et al., 1998; Sawada et al., 2007). We also provide strong evidence of its role in the inflammatory response in macrophages in vitro and after peripheral nerve crush injury in vivo. We present data showing that IL-10 mRNA is robustly upregulated after nerve crush, reaching a maximum level at day 7 . At the protein level, however, there is a gradual increase in IL-10 immunoreactivity in the nerve in the first 2 weeks after injury. Double-immunofluorescence labeling indicates that $\mathrm{CD} 11 \mathrm{~b}^{+}$macrophages are the major cell 


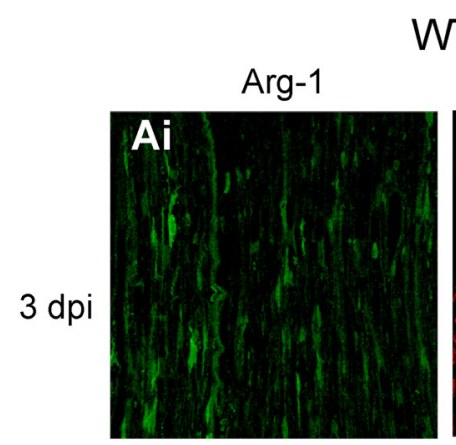

WT

CD11b
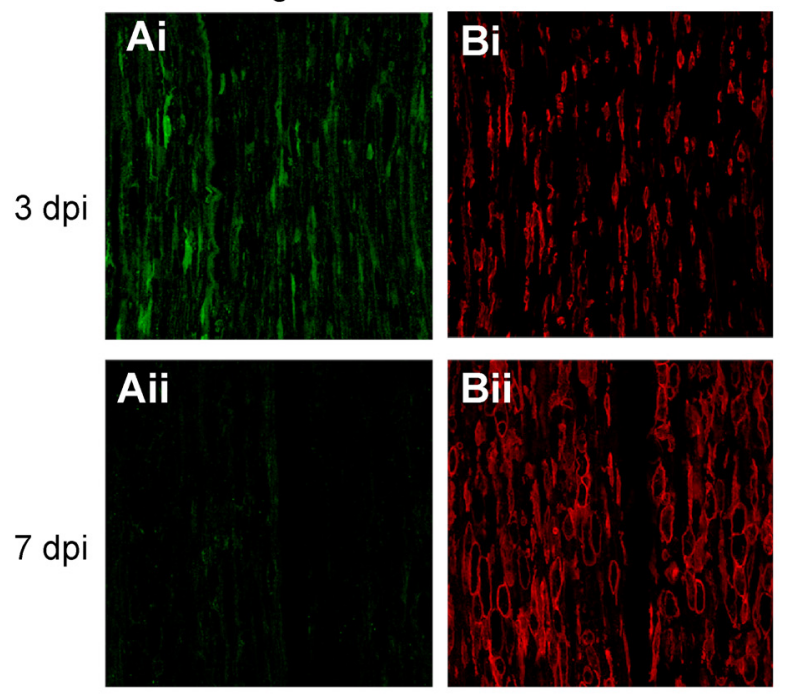

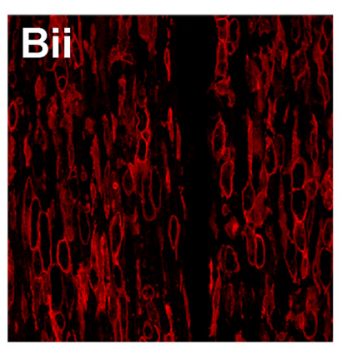

IL10-/-
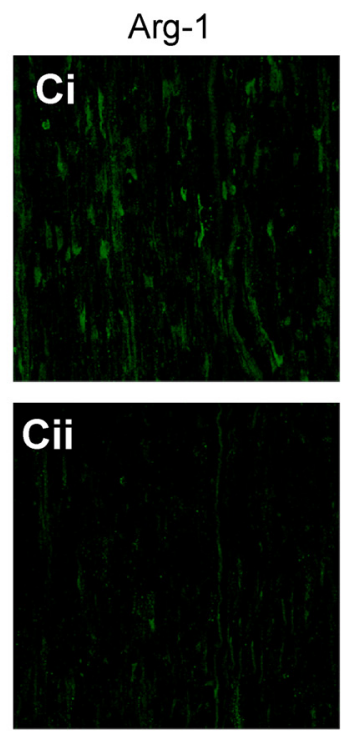

CD11b
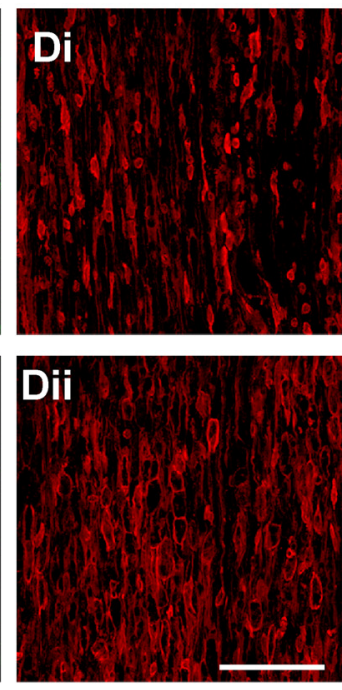

E

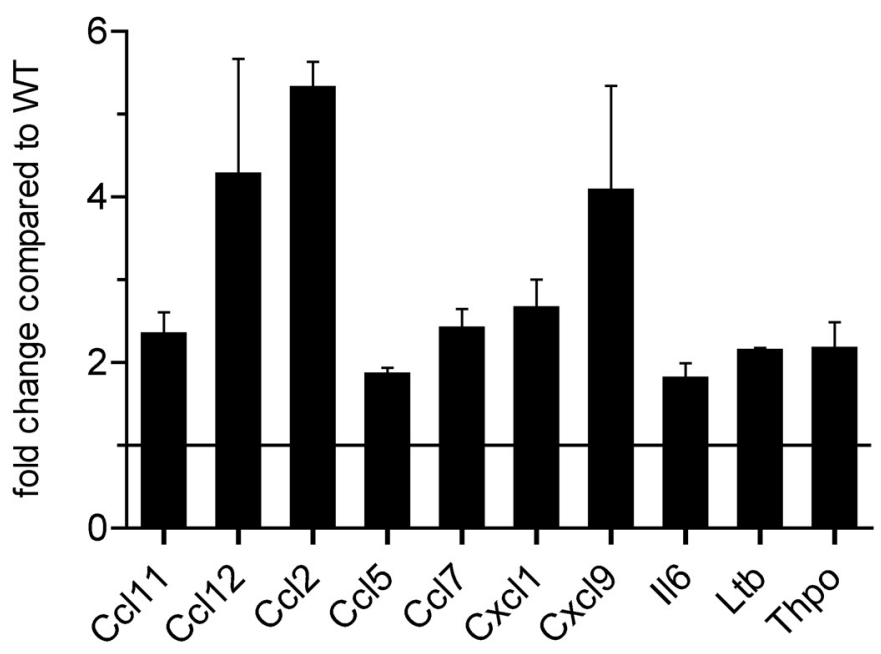

Figure 6. Double-immunofluorescence labeling of Arg-1 in WT $(\boldsymbol{A})$ and IL-10 ${ }^{-1-}(\boldsymbol{C})$ mice at 3 (i) and 7 (ii) days postinjury (dpi). The sections are double labeled for the macrophage marker CD11b ( $\boldsymbol{B}, \boldsymbol{D})$. Note that Arg-1 is expressed in some CD11b ${ }^{+}$macrophages at $3 \mathrm{dpi}$ in WT nerves (Ai) and this is decreased in IL-10 ${ }^{-1-}$ nerves at $3 \mathrm{dpi}(\boldsymbol{C} \boldsymbol{i})$. No Arg- 1 staining is seen at $7 \mathrm{dpi}$ in either genotype (Aii, Cii); note the abundance of CD11b ${ }^{+}$macrophages in these regions. Scale bar, $100 \mu \mathrm{m}$. $\boldsymbol{E}$, Fold increase in the expression of 10 chemokines and cytokines that were statistically significantly increased in IL-10-null nerves compared with WT nerves at $24 \mathrm{~h}$ after crush injury detected with a PCR array screen. The horizontal bar represents level in injured WT nerves. $n=3-4$; $p<0.05$ for all values shown. Il6, Interleukin 6; Ltb, lymphotoxin $\beta$; Thpo, thrombopoietin.

type expressing IL-10 in the injured nerve. Our in vitro work shows that, unlike LPS-stimulated WT BMDM, which markedly reduce expression of proinflammatory chemokines and cytokines in response to myelin phagocytosis, BMDM from IL-10null mice fail to do so. Interestingly, macrophages in mice lacking IL-10 also showed greater expression of M1 markers and reduced expression of M2 markers during the first 3 weeks after sciatic nerve crush injury. Furthermore, a broad PCR array screen for chemokines and cytokines revealed increases in 10 proinflammatory mediators in IL-10-null nerves after crush injury. These data suggest that the lack of IL-10 induces a more proinflammatory environment in the injured sciatic nerve. Consistent with this, there was increased influx and prolonged retention of macrophages after sciatic nerve crush injury in IL-10-null mice accompanied by reduced axonal regeneration and impaired recovery of motor and sensory function. These findings indicate that IL-10, which is mainly expressed in macrophages in the injured mouse sciatic nerve, plays an important role in regulating certain aspects of the proinflammatory response that has an impact on the resolution of inflammation, axon regeneration, and recovery of motor and sensory function.

During WD, macrophages enter the degenerated nerve and phagocytose myelin and axonal debris (Griffin et al., 1992). In vitro studies show that myelin phagocytosis leads to reduction in the expression of proinflammatory cytokines. Recent in vitro work has shown that the increased expression of TNF and IL-12 by LPS-stimulated macrophages is markedly reduced by myelin phagocytosis (Boven et al., 2006; Kroner et al., 2014). In addition, myelin phagocytosis also reduces the expression of various M1 markers and increases the expression of M2 markers by LPSstimulated macrophages; that is, it induces a shift from an M1like to a more M2-like phenotype (Kroner et al., 2014). Although there is some debate currently about what M1 and M2 polarization signify, nevertheless, changes in the expression of these 
A

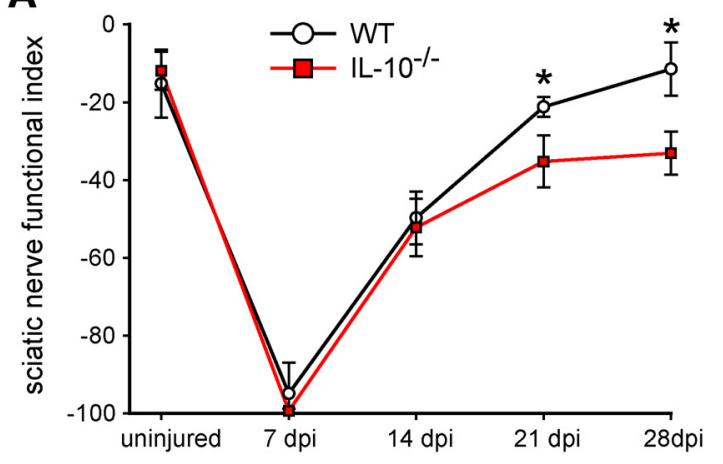

B

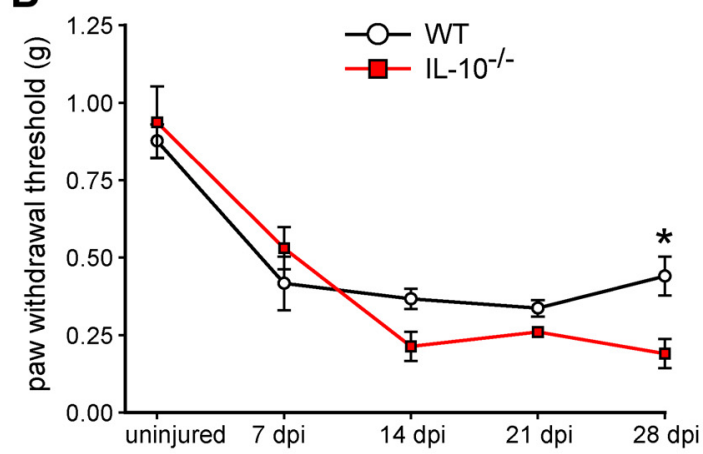

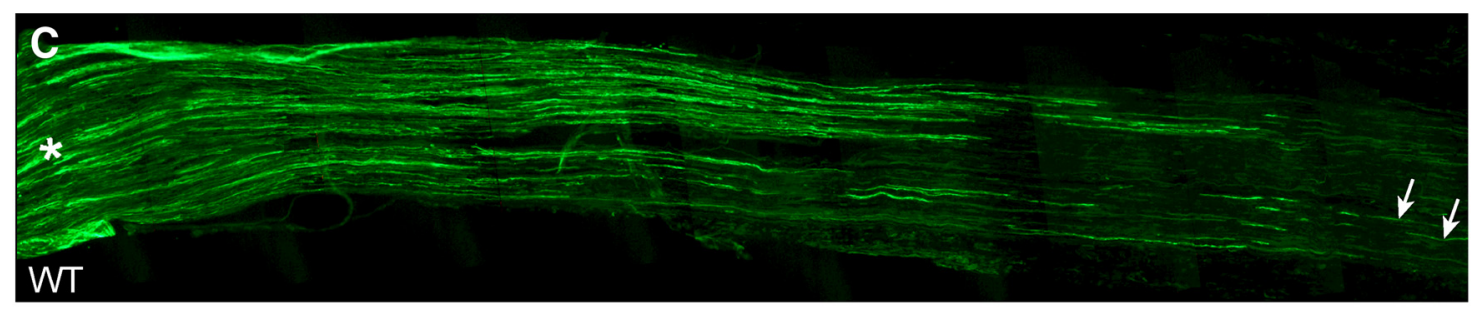

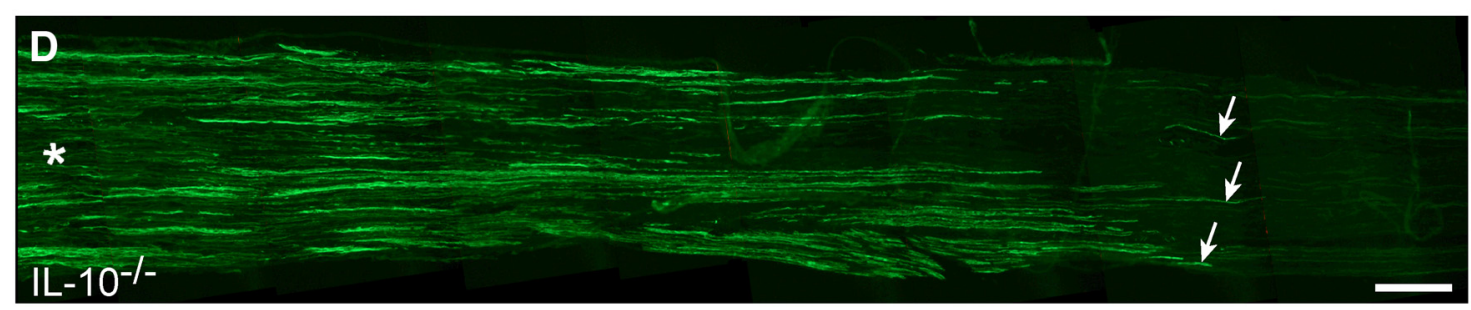

Figure 7. Recovery of motor and sensory function and axon regeneration. $A$, Graph showing motor recovery using the SFI. Note that IL-10-null mice show significantly reduced recovery at 21 and $28 \mathrm{~d}$ postinjury (dpi). $n=5-6$; mean $\pm S D ;{ }^{*} p<0.05$. B , Graph showing sensory recovery assessed using the von Frey hair test. Note that the WT mice begin to show recovery from mechanical allodenia by $28 \mathrm{dpi}$, whereas the IL-10-null mice show no improvement. $n=5$; mean $\pm \mathrm{SEM} ;{ }^{*} p<0.05$. C, $\boldsymbol{D}$, Immunofluorescence labeling for GAP-43 to visualize regenerating axons in WT ( $\boldsymbol{C}$ ) and IL-10 ${ }^{-1-}(\boldsymbol{D})$ nerves at $3 \mathrm{dpi}$; asterisks indicate the proximal end of the nerve near the site of crush injury; arrows indicate labeled axons distally. Note the longer growth in the WT nerve (C) compared with the IL-10 ${ }^{-1-}$ nerve (D); quantification is given in the text. Scale bar, $500 \mu \mathrm{m}$.

markers appear to be coordinated, indicating that macrophages may be induced to move along a continuum from proinflammatory/cytotoxic to an anti-inflammatory/pro-repair state. In the present study, we show that, in the absence of IL-10, BMDM in vitro stimulated with LPS are unable to downregulate the expression of a number of proinflammatory chemokines and cytokines (CCL2, CCL3, CCL4, IL-6, and TNF) in response to myelin phagocytosis. In addition, our PCR array screen of changes in chemokines and cytokines in vivo $24 \mathrm{~h}$ after crush injury showed increased expression of 10 proinflammatory mediators, including CCL2 and IL-6. Furthermore, we also found that macrophages in vivo in degenerating sciatic nerve in IL-10-null mice showed increased expression of M1 markers and decreased expression of M2 markers compared with WT controls. This increased proinflammatory chemokine/cytokine milieu in the injured IL-10-null nerves was accompanied by increased numbers of macrophages at the early (3 d) and later (14, $21 \mathrm{~d}$ ) stages after crush injury. These data suggest that IL-10 may play a role in controlling the recruitment of macrophages during the early period after injury and promoting efflux of macrophages from the injured nerve at later times between 14 and $21 \mathrm{~d}$ after phagocytosis of debris is completed. We reported previously using function-blocking antibodies that CCL2/MCP-1 and CCL3/ MIP- $1 \alpha$ play an important role in the influx of macrophages into the sciatic nerve after crush injury (Perrin et al., 2005). In other work, we reported that intracellular-calcium-dependent group IV (cPLA2 GIVA) and, to a lesser extent, calcium-independent group VIA (iPLA2) induce expression of CCL2/MCP-1 after sciatic nerve crush injury (López-Vales et al., 2008). The present study indicates that IL-10 may play a role in curbing the expression of these chemokines and thereby regulate the influx of macrophages and keep this aspect of the inflammatory response in check. An effective proinflammatory response involving TLR activation and IL-1 $\beta$ signaling is indeed required for myelin clearance and subsequent axon regeneration (Perrin et al., 2005; Karanth et al., 2006; Boivin et al., 2007; Barrette et al., 2008; Nadeau et al., 2011). This inflammation is normally turned off rapidly after nerve injury. Our results suggest that the enhanced and prolonged inflammation in IL-10-null mice leads to detrimental effects on regeneration. Interestingly, studies in nonneural tissues show that IL-10 expression is also induced by TLR2 and TLR4 activation and reduces the expression of various proinflammatory mediators (Ouyang et al., 2011). After myelin and other debris are phagocytosed and axons regenerate and begin to myelinate, macrophages exit the nerve, leading to resolution of inflammation and restoration of tissue homeostasis. Macrophages have to enter into the Schwann cell basal lamina to be able to phagocytose myelin and axonal debris during WD (David et al., 2008). They therefore have to first leave the Schwann cell basal lamina before they can exit the nerve at the end of the period of 
WD (David et al., 2008). We have reported that the exit of macrophages from Schwann cell basal lamina is mediated via Nogo receptors expressed on macrophages interacting with their ligands in newly forming myelin via Rho A-mediated signaling (Fry et al., 2007). After they extrude out of the Schwann cell basal lamina, macrophages are then in a position to leave the nerve (David et al., 2008). We now show that IL-10 plays a role in some aspect of the clearance of macrophages from the nerve because these cells remain in the nerve at later times after injury in IL-10null mice. These data suggest that IL-10 may play a role in curtailing the early proinflammatory response after nerve injury and also promote the resolution of inflammation at later stages.

We show that the injured IL-10-null nerves express higher levels of various proinflammatory chemokines and cytokines and contain increased numbers of macrophages during the period of WD. Interestingly, axon regeneration assessed with GAP-43 labeling is impaired in this proinflammatory environment of the injured IL-10-null nerves compared with WT mice. Furthermore, the poor axon regeneration in the injured IL-10 nerves is associated with poor recovery of motor and sensory function assayed with the SFI and von Frey hair test, respectively. The loss of SFI immediately after crush injury is due to the paralysis of the dorsal interosseous muscles of the foot required for the spreading or abduction of the toes, which is a key measure of the SFI. The SFI values return to normal as the nerve regenerates and reinnervates the abductor muscles of the toes. The SFI is therefore a good measure of recovery of motor innervation of the foot muscles. In contrast, the mechanical allodynia that is seen after nerve injury recover only partially during the same 4 week period. These findings on the effects of IL-10 are supported by earlier studies reporting that a single injection of IL-10 limits proinflammatory cytokine-mediated inflammatory hyperalgesia (Poole et al., 1995; Vale et al., 2003). However, the effect of IL-10 on axon regeneration is not clearly established (Atkins et al., 2007; Sakalidou et al., 2011). Our results show that the absence of IL-10 impairs axon regeneration and has an effect on both motor and sensory recovery. Inflammation in the injured CNS is thought to contribute importantly to secondary damage and worsening outcome (Kroner et al., 2015). In the injured spinal cord, the inflammatory response involving macrophages is rapid and remains prolonged (David et al., 2012a; Kroner et al., 2015) and blocking various aspects of this proinflammatory response improves outcome (Popovich et al., 1999; David et al., 2012b). Interestingly, after peripheral nerve injury, a rapid and robust proinflammatory response involving TLR signaling and IL- $1 \beta$ is required for efficient removal of myelin and axonal debris and provides the conditions necessary for axon regeneration (Boivin et al., 2007; Nadeau et al., 2011; Bastien and Lacroix, 2014). An important difference between the CNS and peripheral nerve response to injury is that, in peripheral nerves, inflammation is initiated rapidly and switched off by $2-3$ weeks. This timely resolution of inflammation in peripheral nerves is thought to underlie the effective regeneration and remyelination seen after injury. However, direct evidence of this was lacking. Many different molecular mechanisms may underlie this resolution program. We now provide evidence that IL-10 may contribute importantly to curtailing the inflammatory response after sciatic nerve crush injury and thus promote resolution of inflammation and effective nerve repair. Interestingly, in the CNS, systemic treatment with IL-10 improves outcome after spinal cord injury (Bethea et al., 1999) and recent work has shown that the beneficial effects of chondroitinase ABC treatment after spinal cord injury may be due in part to increased expression of IL-10 (Didangelos et al., 2014). Our data show that, in the absence of IL-10, the increased proinflammatory milieu of the injured peripheral nerve leads to impairment of axon regeneration and loss of motor and sensory recovery, indicating that IL-10 plays an important role in modulating inflammation and promoting regeneration in peripheral nerves.

\section{References}

Atkins S, Loescher AR, Boissonade FM, Smith KG, Occleston N, O'Kane S, Ferguson MW, Robinson PP (2007) Interleukin-10 reduces scarring and enhances regeneration at a site of sciatic nerve repair. J Peripher Nerv Syst 12:269-276. CrossRef Medline

Barrette B, Hébert MA, Filali M, Lafortune K, Vallières N, Gowing G, Julien JP, Lacroix S (2008) Requirement of myeloid cells for axon regeneration. J Neurosci 28:9363-9376. CrossRef Medline

Bastien D, Lacroix S (2014) Cytokine pathways regulating glial and leukocyte function after spinal cord and peripheral nerve injury. Exp Neurol 258:62-77. CrossRef Medline

Be'eri H, Reichert F, Saada A, Rotshenker S (1998) The cytokine network of Wallerian degeneration: IL-10 and GM-CSF. Eur J Neurosci 10:27072713. CrossRef Medline

Bethea JR, Nagashima H, Acosta MC, Briceno C, Gomez F, Marcillo AE, Loor K, Green J, Dietrich WD (1999) Systemically administered interleukin-10 reduces tumor necrosis factor-alpha production and significantly improves functional recovery following traumatic spinal cord injury in rats. J Neurotrauma 16:851-863. CrossRef Medline

Boivin A, Pineau I, Barrette B, Filali M, Vallières N, Rivest S, Lacroix S (2007) Toll-like receptor signaling is critical for Wallerian degeneration and functional recovery after peripheral nerve injury. J Neurosci 27:1256512576. CrossRef Medline

Boven LA, Van Meurs M, Van Zwam M, Wierenga-Wolf A, Hintzen RQ, Boot RG, Aerts JM, Amor S, Nieuwenhuis EE, Laman JD (2006) Myelinladen macrophages are anti-inflammatory, consistent with foam cells in multiple sclerosis. Brain 129:517-526. Medline

Brück W (1997) The role of macrophages in Wallerian degeneration. Brain Pathol 7:741-752. CrossRef Medline

Brück W, Huitinga I, Dijkstra CD (1996) Liposome-mediated monocyte depletion during Wallerian degeneration defines the role of hematogenous phagocytes in myelin removal. J Neurosci Res 46:477-484. Medline

Chaplan SR, Bach FW, Pogrel JW, Chung JM, Yaksh TL (1994) Quantitative assessment of tactile allodynia in the rat paw. J Neurosci Methods 53: 55-63. CrossRef Medline

Chen P, Cescon M, Zuccolotto G, Nobbio L, Colombelli C, Filaferro M, Vitale G, Feltri ML, Bonaldo P (2015) Collagen VI regulates peripheral nerve regeneration by modulating macrophage recruitment and polarization. Acta Neuropathol 129:97-113. CrossRef Medline

David S, Kroner A (2011) Repertoire of microglial and macrophage responses after spinal cord injury. Nat Rev Neurosci 12:388-399. CrossRef Medline

David S, Braun PE, Jackson DL, Kottis V, McKerracher L (1995) Laminin overrides the inhibitory effects of peripheral nervous system and central nervous system myelin-derived inhibitors of neurite growth. J Neurosci Res 42:594-602. CrossRef Medline

David S, Fry EJ, López-Vales R (2008) Novel roles for Nogo receptor in inflammation and disease. Trends Neurosci 31:221-226. CrossRef Medline

David S, López-Vales R, Wee Yong V (2012a) Harmful and beneficial effects of inflammation after spinal cord injury: potential therapeutic implications. Handb Clin Neurol 109:485-502. CrossRef Medline

David S, Zarruk JG, Ghasemlou N (2012b) Inflammatory pathways in spinal cord injury. Int Rev Neurobiol 106:127-152. CrossRef Medline

David S, Greenhalgh AD, Kroner A (2015) Macrophage and microglial plasticity in the injured spinal cord. Neuroscience 307:311-318. CrossRef Medline

Didangelos A, Iberl M, Vinsland E, Bartus K, Bradbury EJ (2014) Regulation of IL-10 by chondroitinase $\mathrm{ABC}$ promotes a distinct immune response following spinal cord injury. J Neurosci 34:16424-16432. CrossRef Medline

Filbin MT (2003) Myelin-associated inhibitors of axonal regeneration in the adult mammalian CNS. Nat Rev Neurosci 4:703-713. CrossRef Medline

Fry EJ, Ho C, David S (2007) A role for Nogo receptor in macrophage clearance from injured peripheral nerve. Neuron 53:649-662. CrossRef Medline

Gillen C, Jander S, Stoll G (1998) Sequential expression of mRNA for pro- 
inflammatory cytokines and interleukin-10 in the rat peripheral nervous system: comparison between immune-mediated demyelination and Wallerian degeneration. J Neurosci Res 51:489-496. Medline

Gordon S, Taylor PR (2005) Monocyte and macrophage heterogeneity. Nat Rev Immunol 5:953-964. CrossRef Medline

Griffin JW, George R, Lobato C, Tyor WR, Yan LC, Glass JD (1992) Macrophage responses and myelin clearance during Wallerian degeneration: relevance to immune-mediated demyelination. J Neuroimmunol 40: 153-165. CrossRef Medline

Inserra MM, Bloch DA, Terris DJ (1998) Functional indices for sciatic, peroneal, and posterior tibial nerve lesions in the mouse. Microsurgery 18: 119-124. Medline

Karanth S, Yang G, Yeh J, Richardson PM (2006) Nature of signals that initiate the immune response during Wallerian degeneration of peripheral nerves. Exp Neurol 202:161-166. CrossRef Medline

Kigerl KA, Gensel JC, Ankeny DP, Alexander JK, Donnelly DJ, Popovich PG (2009) Identification of two distinct macrophage subsets with divergent effects causing either neurotoxicity or regeneration in the injured mouse spinal cord. J Neurosci 29:13435-13444. CrossRef Medline

Kroner A, Greenhalgh AD, Zarruk JG, Passos Dos Santos R, Gaestel M, David S (2014) TNF and increased intracellular iron alter macrophage polarization to a detrimental M1 phenotype in the injured spinal cord. Neuron 83:1098-1116. CrossRef Medline

Kroner A, Greenhalgh, A, and David, S (2015) Microglia and macrophage responses and their role after spinal cord injury. In: Neuroinflammation: new insights into beneficial and detrimental functions (David S, ed), pp 53-70. New Jersey: Wiley Blackwell.

Livak KJ, Schmittgen TD (2001) Analysis of relative gene expression data using real-time quantitative PCR and the 2(-delta delta $\mathrm{C}(\mathrm{T})$ ) method. Methods 25:402-408. CrossRef Medline

López-Vales R, Navarro X, Shimizu T, Baskakis C, Kokotos G, ConstantinouKokotou V, Stephens D, Dennis EA, David S (2008) Intracellular phospholipase $\mathrm{A}(2)$ group IVA and group VIA play important roles in Wallerian degeneration and axon regeneration after peripheral nerve injury. Brain 131:2620-2631. CrossRef Medline

Ma CH, Brenner GJ, Omura T, Samad OA, Costigan M, Inquimbert P, Niederkofler V, Salie R, Sun CC, Lin HY, Arber S, Coppola G, Woolf CJ, Samad TA (2011) The BMP coreceptor RGMb promotes while the endogenous BMP antagonist noggin reduces neurite outgrowth and peripheral nerve regeneration by modulating BMP signaling. J Neurosci 31: 18391-18400. CrossRef Medline

Mantovani A, Locati M (2009) Orchestration of macrophage polarization. Blood 114:3135-3136. CrossRef Medline

Martini R, Fischer S, López-Vales R, David S (2008) Interactions between Schwann cells and macrophages in injury and inherited demyelinating disease. Glia 56:1566-1577. CrossRef Medline

Mietto BS, Jurgensen S, Alves L, Pecli C, Narciso MS, Assunção-Miranda I, Villa-Verde DM, de Souza Lima FR, de Menezes JR, Benjamim CF, Bozza MT, Martinez AM (2013) Lack of galectin-3 speeds Wallerian degeneration by altering TLR and proinflammatory cytokine expressions in injured sciatic nerve. Eur J Neurosci 37:1682-1690. CrossRef Medline

Mietto BS, Mostacada K, Martinez AM (2015) Neurotrauma and inflammation: CNS and PNS responses. Mediators Inflamm 2015:251204. Medline

Mueller M, Wacker K, Ringelstein EB, Hickey WF, Imai Y, Kiefer R (2001) Rapid response of identified resident endoneurial macrophages to nerve injury. Am J Pathol 159:2187-2197. CrossRef Medline

Mueller M, Leonhard C, Wacker K, Ringelstein EB, Okabe M, Hickey WF, Kiefer R (2003) Macrophage response to peripheral nerve injury: the quantitative contribution of resident and hematogenous macrophages. Lab Invest 83:175-185. CrossRef Medline

Murray PJ, Allen JE, Biswas SK, Fisher EA, Gilroy DW, Goerdt S, Gordon S, Hamilton JA, Ivashkiv LB, Lawrence T, Locati M, Mantovani A, Martinez FO, Mege JL, Mosser DM, Natoli G, Saeij JP, Schultze JL, Shirey KA, Sica A, et al. (2014) Macrophage activation and polarization: nomenclature and experimental guidelines. Immunity 41:14-20. CrossRef Medline
Nadeau S, Filali M, Zhang J, Kerr BJ, Rivest S, Soulet D, Iwakura Y, de Rivero Vaccari JP, Keane RW, Lacroix S (2011) Functional recovery after peripheral nerve injury is dependent on the proinflammatory cytokines IL-1beta and TNF: implications for neuropathic pain. J Neurosci 31: 12533-12542. CrossRef Medline

Niemi JP, DeFrancesco-Lisowitz A, Cregg JM, Howarth M, Zigmond RE (2015) Overexpression of the monocyte chemokine CCL2 in dorsal root ganglion neurons causes a conditioning-like increase in neurite outgrowth and does so via a STAT3 dependent mechanism. Exp Neurol 275P3:25-37. Medline

Ouyang W, Rutz S, Crellin NK, Valdez PA, Hymowitz SG (2011) Regulation and functions of the IL-10 family of cytokines in inflammation and disease. Annu Rev Immunol 29:71-109. CrossRef Medline

Perrin FE, Lacroix S, Avilés-Trigueros M, David S (2005) Involvement of monocyte chemoattractant protein-1, macrophage inflammatory protein-1alpha and interleukin-1beta in Wallerian degeneration. Brain 128:854-866. CrossRef Medline

Poole S, Cunha FQ, Selkirk S, Lorenzetti BB, Ferreira SH (1995) Cytokinemediated inflammatory hyperalgesia limited by interleukin-10. Br J Pharmacol 115:684-688. CrossRef Medline

Popovich PG, Guan Z, Wei P, Huitinga I, van Rooijen N, Stokes BT (1999) Depletion of hematogenous macrophages promotes partial hindlimb recovery and neuroanatomical repair after experimental spinal cord injury. Exp Neurol 158:351-365. CrossRef Medline

Sakalidou M, Leibig N, Boyle V, Koulaxouzidis G, Penna V (2011) Interleukin-10 and regeneration in an end-to-side nerve repair model of the rat. J Peripher Nerv Syst 16:334-340. CrossRef Medline

Sawada T, Sano M, Omura T, Omura K, Hasegawa T, Funahashi S, Nagano A (2007) Spatiotemporal quantification of tumor necrosis factor-alpha and interleukin-10 after crush injury in rat sciatic nerve utilizing immunohistochemistry. Neurosci Lett 417:55-60. CrossRef Medline

Shamash S, Reichert F, Rotshenker S (2002) The cytokine network of Wallerian degeneration: tumor necrosis factor-alpha, interleukin-1alpha, and interleukin-1beta. J Neurosci 22:3052-3060. Medline

Shen ZL, Lassner F, Bader A, Becker M, Walter GF, Berger A (2000) Cellular activity of resident macrophages during Wallerian degeneration. Microsurgery 20:255-261. CrossRef Medline

Stoll G, Griffin JW, Li CY, Trapp BD (1989) Wallerian degeneration in the peripheral nervous system: participation of both Schwann cells and macrophages in myelin degradation. J Neurocytol 18:671-683. CrossRef Medline

Subang MC, Richardson PM (2001) Influence of injury and cytokines on synthesis of monocyte chemoattractant protein-1 mRNA in peripheral nervous tissue. Eur J Neurosci 13:521-528. CrossRef Medline

Taskinen HS, Röyttä M (1997) The dynamics of macrophage recruitment after nerve transection. Acta Neuropathol 93:252-259. CrossRef Medline

Taskinen HS, Röyttä M (2000) Increased expression of chemokines (MCP-1, MIP-1alpha, RANTES) after peripheral nerve transection. J Peripher Nerv Syst 5:75-81. CrossRef Medline

Toews AD, Barrett C, Morell P (1998) Monocyte chemoattractant protein 1 is responsible for macrophage recruitment following injury to sciatic nerve. J Neurosci Res 53:260-267. Medline

Vale ML, Marques JB, Moreira CA, Rocha FA, Ferreira SH, Poole S, Cunha FQ, Ribeiro RA (2003) Antinociceptive effects of interleukin-4, -10, and -13 on the writhing response in mice and zymosan-induced knee joint incapacitation in rats. J Pharmacol Exp Ther 304:102-108. CrossRef Medline

van Rossum D, Hilbert S, Strassenburg S, Hanisch UK, Brück W (2008) Myelin-phagocytosing macrophages in isolated sciatic and optic nerves reveal a unique reactive phenotype. Glia 56:271-283. CrossRef Medline

Ydens E, Cauwels A, Asselbergh B, Goethals S, Peeraer L, Lornet G, AlmeidaSouza L, Van Ginderachter JA, Timmerman V, Janssens S (2012) Acute injury in the peripheral nervous system triggers an alternative macrophage response. J Neuroinflammation 9:176. CrossRef Medline 